\title{
Reutilização de seringas descartáveis no domicílio de crianças e adolescentes com diabetes mellitus*
}

\author{
REUSE OF DISCARDED SYRINGES IN RESIDENCES OF CHILDREN AND TEENAGERS \\ WITHDIABETES MELLITUS
}

\author{
REUTILIZACION DE JERINGUILLAS DESECHABLES EN EL DOMICILIO DE NIÑOS Y \\ ADOLESCENTES CON DIABETES MELLITUS
}

\section{Ampario del Rocio Vintimilla Castro ${ }^{1}$, Sonia Aurora Alves Grossi²}

\section{RESUMO}

$\mathrm{O}$ fornecimento inadequado ou insuficiente de medicações e materiais para aplicar insulina, leva às famílias a adotarem estratégias variadas, como a prática de reutilização de seringas na tentativa de minimizar os custos com a doença. Objetivos: avaliar a prática de preparo e aplicação de insulina, evidenciar alterações freqüentes nos locais de aplicação de insulina. Este estudo foi comparativo, transversal, com 199 crianças e adolescentes diabéticos do Ambulatório do Instituto da Criança de São Paulo. Dividiu-se em Grupo Aque reutiliza seringas descartáveis e Grupo B não as reutiliza. Estratégia comum foi o reencape da agulha sem limpeza prévia, guarda dentro ou fora da geladeira em recipiente fechado. Maior queixa foi a dor. O Hospital e o enfermeiro foram os responsáveis pela orientação dessa prática.

\section{DESCRITORES}

Reutilização de equipamento. Uso comum de agulhas e seringas. Diabetes mellitus.

Enfermagem pediátrica.

\section{ABSTRACT}

Inadequate or insufficient supply of medication and material to apply insulin leads families to resort to a variety of strategies, such as the practice of reusing dischargeable syringes in order to reduce the expenses with the illness. This is a study aimed at evaluating the practice of insulin application, analyzing the practice of syringe reuse and describing the most frequent changes of application sites. It is a comparative, transversal survey carried out with 199 diabetic children and adolescents. It was developed at the diabetes' Outpatient Unit of the Hospital das Clínicas' Child Institute, of the University of São Paulo's School of Medicine. The studied population was divided in two groups: in Group A were those who reused the syringes, and in Group B those who did not. A common strategy was rewrapping the needle without previously cleaning it and keeping it inside or outside the refrigerator in a closed container. The most common complaint was pain. The hospital and the nurse were responsible for the orientation for that practice.

\section{KEY WORDS}

Equipment reuse.

Needle sharing.

Diabetes mellitus.

Pediatric nursing.

\section{RESUMEN}

El fornecimiento inadecuado o insuficiente de medicaciones y materiales para aplicar insulina lleva a las familias a adoptar varias estrategias como la práctica de reutilización de jeringuillas intentando minimizar los costos con la enfermedad. Objetivos: evaluar la práctica del preparo y de la aplicación de insulina y evidenciar alteraciones frecuentes en esos locales. Este estudio fue comparativo, transversal con 199 niños y adolescentes diabéticos de Consulta Externa del Instituto del Niño del Hospital de las Clínicas de São Paulo. El grupo fue dividido en: Grupo A que reutiliza jeringuillas desechables y Grupo B que no reutiliza. El re encape de la aguja sin limpieza previa, guardan las jeringuillas dentro del refrigerador y fuera del refrigerador, guardan generalmente en recipientes cerrados. Hubo relato de dolor en . El hospital y el enfermero fueron los responsables por la orientación dada .

\footnotetext{
* Extraído da

dissertação:

"Reutilização de

seringas descartáveis

para aplicação de

insulina: uma prática comum no domicílio

de pacientes com

diabetes mellitus".

Escola de Enfermagem

da Universidade de

São Paulo, 2005

1 Mestre em

Enfermagem na

Saúde do Adulto pela

Escola de Enfermagem da Universidade de

São Paulo.

Enfermeira Pediátrica.

Supervisora de Seção Hospitalar da Unidade de Especialidades II

do Instituto da Criança do Hospital das Clínicas da Faculdade de Medicina da Universidade de São Paulo -

amparito@ig.com.br 2 Professora Doutora do Departamento Médico-Cirúrgico da Escola de Enfermagem da Universidade de São Paulo sogrossi@usp.br
}

DESCRIPTORES

Equipo reutilizado

Compartimiento de agujas.

Diabetes mellitus.

Enfermería pediátrica. 


\section{INTRODUÇÃO}

Com elevadas taxas de morbi-mortalidade, o diabetes transformou-se em problema de saúde pública de proporções endêmicas. Com mais de 100 milhões de casos no mundo a tendência é aumentar nos próximos dez anos ${ }^{(1)}$.

A terapêutica intensiva ideal, preconizada pelo Diabetes Control and Complications Trial, mantêm a doença controlada e diminui ou prevêem complicações agudas e crônicas ao longo da vida ${ }^{(2)}$. Esta terapêutica inclui monitorização intensiva com quatro medidas diárias de glicemia capilar e aplicação de insulina fracionada de três vezes ou mais ao dia, o que envolve a compra de maior número de seringas. Essa problemática favorece a adaptação de estratégias variadas pelos responsáveis de crianças e adolescentes com diabetes mellitus do tipo 1. Na tentativa de minimizar os custos com a doença, tanto os pais quanto os pacientes, principalmente adolescentes, reutilizam as seringas descartáveis para aplicação de insulina, como se observa na prática.

Nesta perspectiva de terapêutica intensiva, os custos e a necessidade de atenção para com a clientela diabética aumentaram consideravelmente, o que tem gerado conflitos econômicos para os responsáveis dos pacientes com diabetes. Dessa forma ao relacionar o salário brasileiro com esses gastos, torna-se incompatível com o custo da manutenção do diabetes o que poderia levar à prática de reutilização ${ }^{(3-4)}$. Isso tem criado polêmica nas instituições, entre profissionais de saúde bem como nas entidades governamentais, que não dispõem de recursos humanos e materiais para dar suporte adequado ao tratamento.

Nossa realidade mostra que não há o fornecimento geral e regular de seringas, fitas de glicemia capilar e insulina para a clientela diabética, agravando a situação econômica e emocional do paciente e da família. Este panorama torna-se contraditório frente à existência da Lei Estadual n ${ }^{\circ} 10782$ de 9 de março de 2001, que declara em seu artigo $1^{\circ}$ que o Sistema Único de Saúde (SUS) prestará atenção integral à pessoa diabética em todos as suas formas, tendo como diretrizes a universalidade, integralidade, eqüidade, descentralização das ações e dos serviços de saúde, bem como o direito à medicação e aos instrumentos e materiais de auto-aplicação e autocontrole. Já o artigo $3^{\circ}$ declara que a direção do SUS Estadual e Municipal garantirá o fornecimento universal de materiais suficientes para o auto controle do diabetes e dos procedimentos necessários e integrais ${ }^{(5)}$. Apesar de existir essa lei e não se aplicar regularmente, os responsáveis das crianças e adolescentes são obrigados a comprar materiais e medicação, com recursos próprios tentando minimizar os gastos pela difícil condição financeira. Dessa forma a clien- tela pediátrica adere à prática de reutilização de seringas descartáveis de forma forçada com tendência a mantê-la por muito tempo.

É necessário ressaltar que a quantidade de dinheiro separado mensalmente do orçamento familiar, para manter o diabetes, representa grande impacto pessoal, social e financeiro. Isso leva a redução drástica do nível de vida e estabelece, provavelmente, percepção negativa da doença através da tristeza, estresse e ansiedade ${ }^{(6)}$. Assim, torna-se difícil a implementação eficiente da terapêutica intensiva no manejo do diabetes, o que nos leva a refletir sobre os problemas econômicos da clientela diabética e as dificuldades do sistema de saúde.

Dessa forma ao reconhecer o impacto dos custos com o tratamento do diabetes mellitus-DM1 (Diabetes Mellitus tipo 1) e considerando nossa experiência junto a crianças e adolescentes com essa doença, pode-se afirmar que a terapêutica intensiva é onerosa, impossibilitando o descarte da seringa após seu uso, conforme preconizam a Agência Nacional de Vigilância Sanitária (ANVISA) e os fabricantes de seringas ${ }^{(7-8)}$. Percebe-se que muitas famílias carecem meios financeiros ou mantêm uma renda incompatível com os gastos da doença; assim sendo, considera-se de fundamental importância a busca de caminhos assistenciais que levem em conta as dificuldades pessoais dos diabéticos para manter um bom controle da doença ${ }^{(9)}$. Um estudo ${ }^{(10)}$ enfatiza a importância da adoção de estratégias alternativas para o controle do diabetes visando as necessidades dos pacientes de forma individual e a situação dos recursos humanos e financeiros do sistema de saúde.

A partir desses pressupostos, desenvolvemos o presente estudo, que tem como objetivos descrever as características sócio-econômicas e demográficas dos pacientes pediátricos com diabetes mellitus, avaliar a prática de insulinoterapia, analisar a prática de reutilização, comparar as alterações mais freqüentes nos locais de aplicação de insulina dos pacientes que reutilizam seringas descartáveis dos que não reutilizam seringas e associar essas complicações à prática de insulinoterapia em relação ao tamanho de agulha, insulinas fixas diárias, número de reutilizações.

\section{CASUÍSTICA E MÉTODO}

Estudo descritivo, comparativo, analítico e transversal com abordagem quantitativa, desenvolvido no ambulatório de diabetes do Instituto da Criança da Faculdade de Medicina da Universidade de São Paulo-FMUSP. A população foi constituída de 199 crianças e adolescentes menores de 19 anos de idade de ambos sexos. A população foi dividida em Grupo A (153 pacientes) que reutiliza seringas descartáveis e Grupo B (46 pacientes) que não reutiliza seringas 
descartáveis. Para coletar os dados, utilizou-se um formulário constituído por cinco partes contendo 26 perguntas fechadas de múltipla escolha.

Os dados foram coletados, no próprio ambulatório de diabetes, de abril a novembro de 2004 e transportados para o programa Excel para serem processados no programa estatístico SPSS (Statistical Package for the Social Sciences) versão 12 para o Windows. Algumas variáveis qualitativas e quantitativas foram apresentadas em tabelas de freqüências absolutas e relativas. Para comparação das medianas entre os grupos $\mathrm{A}$ e $\mathrm{B}$ em relação às variáveis, idade, tempo de doença e renda familiar foi usado o teste não paramétrico de Mann-Whitney. Para associar a freqüência de nódulos e lipohipertrofias nos locais de aplicação de insulina nos grupos A e B, foi utilizado o teste de Fisher. Para a associação entre as variáveis, tamanho da agulha, insulina fixa da população e o número de reutilização do Grupo A com as variáveis lipohipertrofias e nódulos, nos locais de aplicação de insulina, utilizou-se o teste $\mathrm{c}^{2}$ (Qui-quadrado). Nas análises estatísticas foi adotado o nível de significância de 5\% .

O projeto foi encaminhado e aprovado pelo Comitê de Ética e Pesquisa do Instituto da Criança e do Departamento de Pediatria da Faculdade de Medicina da Universidade de São Paulo e pela Comissão de Ética para Análise de Projetos de Pesquisa (CAPPesq) da Diretoria Clínica do Hospital das Clínicas da Universidade de São Paulo em 16/06/2004 sob número de protocolo 218/04. O termo de consentimento livre e esclarecido foi entregue, aos responsáveis dos pacientes, após explicação, outra cópia assinada foi arquivada no prontuário do paciente.

\section{RESULTADOS}

Os resultados serão apresentados de acordo com a seqüência dos objetivos propostos para a presente investigação. De acordo com a descrição das características da população houve predominância do sexo feminino 130/199 (65,3\%), em relação ao masculino 69/199 (34,7\%). Quanto à escolaridade, 102/199 (51,3\%) pacientes possuem Ensino Fundamental, seguido pelo Ensino Médio 54/199 (27,2\%). Os responsáveis possuem Ensino Fundamental incompleto, seguido pelo Médio completo 45/199 (22,6\%). Houve responsáveis com escolaridade superior completa $5 / 199(2,5 \%)$ ou incompleta $9 / 199(4,5 \%)$. No que tange a procedência dos pacientes, 107/199 (53,8\%) são de São Paulo capital e 92/199 (46,2\%) são da Grande São Paulo. A renda mensal variou de meio a mais de 20 salários mínimos com predomínio de 1 a 2 salários mínimos, 97/199 (48,8\%), seguida de 3 a 5 salários, $47 / 199(23,6 \%)$ e de 5 a 9 salários, 25/199 (12,6\%). Constatou-se que $130 / 199(65,3 \%)$ dos pacientes compraram as seringas na farmácia, somente $50 / 199(25,1 \%)$ as conseguiam na Unidade Básica de Saúde e 19/199 (9,6\%) as obtiveram, seja por doação ou em outros lugares como hospitais ou Secre- tarias de Saúde. Verificou-se que 130/199 (100\%) gastaram de 8 a 199 reais, sendo que $107 / 130(82,4 \%)$ tiveram o maior gasto de 20 a 79 reais.

Os responsáveis pela aplicação de insulina foram os próprios pacientes que aplicaram a insulina 111/199 (55,7\%), contudo a mãe também teve participação, 77/199 (38,7\%). Observou-se que, 194/199 (97,5\%) lavaram as mãos antes do preparo e aplicação de insulina e 5/199 (2,5\%) não lavaram. Verificou-se que, $151 / 199(75,9 \%)$ preferiram seringa com agulha acoplada, enquanto que 48/199 (24,1\%) optaram pela seringa com agulha não acoplada. Observou-se que 188/199 (94,5\%) da população utilizou algum tipo de álcool, seja de supermercado a $70 \%$ ou em forma de gel para desinfetar a tampa do frasco de insulina. No entanto o mais utilizado foi o álcool de supermercado em 116/199 (58,3\%). Para a assepsia da pele 191/199 (96\%) também utilizam com freqüência o álcool de supermercado (54,3\%), seguido pelo álcool a 70\% $(30,7 \%)$. Outros produtos encontrados, na tentativa de antisepsia da pele, foram água e sabão, soro fisiológico a $0,9 \% \mathrm{e}$ bicarbonato de sódio 8/199(4,0\%).

O local preferencial para aplicação de insulina foi o braço, sendo a coxa o segundo local preferido, seguido pelo glúteo e abdômen. Todos os locais de aplicação foram utilizados, sendo que $25 \%$ da população não utilizou o abdômen. O Grupo A referiu aplicar a insulina no braço como primeira opção, seguida pela coxa. No entanto o Grupo B referiu preferir o glúteo. Contudo quase todos os locais de aplicação foram utilizados pelos dois grupos, exceto o grupo B que não utilizou o abdômen $(45,7 \%)$. Constatou-se que $117 / 199(58,8 \%)$ administraram a insulina de uma a três vezes no mesmo local durante uma semana e 69/199 (34,7\%) aplicaram a insulina de sete a oito vezes no mesmo local semanalmente. A média obtida foi de três aplicações por semana no mesmo local.

A comparação dos grupos A e B segundo idade, tempo de doença e renda familiar apontou que do total de 199 pacientes, o Grupo A, 153 (76,88\%) reutilizou as seringas descartáveis e o Grupo B não as reutilizou 46 (23,12\%). A distribuição das idades no grupo A apresentou uma curva aproximadamente normal ou gaussiana com uma média de 11,35 anos, mediana de 12 anos e um desvio padrão de 4,53 anos. A distribuição da idade (anos) do grupo B teve uma curva aproximadamente normal com uma média de 9,13 anos, mediana de 8 anos, desvio padrão 4,47 anos.

A diferença encontrada entre as medianas da idade nos grupos A e B, segundo o teste não paramêtrico de MannWithney, foi estatisticamente significante $(p=0.003)$, ou seja, o grupo A, que apresentou a maior média de idade, é o que reutiliza seringas descartáveis. A distribuição de tempo de doença no grupo A é desviada à direita, apresentando uma mediana de 4 anos e um intervalo de variação de 16 anos. 
No que diz respeito à distribuição do tempo de doença, o grupo $\mathrm{B}$ apresentou uma curva desviada à direita com uma mediana de 3 anos e um intervalo de variação de 15 anos. Não houve diferença estatisticamente significante em relação ao tempo de doença $(\mathrm{p}=0,105)$.

A variável renda, apresentada na forma de faixas e comparada através das medianas das faixas de renda nos dois grupos não encontrou diferença estatisticamente significante $(\mathrm{p}=0,760)$.

Em relação à análise da prática de reutilização em relação ao tempo, número de reuso, estratégias de reutilização, local e forma de armazenamento do material, motivo de troca de seringa, local de aprendizado e responsável pela orientação dessa prática constatou-se que:

Em relação ao tempo de reutilização das seringas descartáveis, houve uma variação de menos de 1 ano a 10 anos ou mais, sendo que a predominância maior foi até 2 anos, 81/199 (52\%). Constatou-se que 45/199 (29,4\%) reutilizaram entre 4 a 5 anos. Em relação à freqüência de reaproveitamento das seringas, houve uma freqüência de reutilização de 1 a 19 vezes, sendo que a maioria 119/199 $(77,8 \%)$ reutilizou de 1 a 4 vezes. Observou-se que 92/199 $(60,1 \%)$ da população reencapa a agulha com o próprio protetor sem limpá-las previamente. O êmbolo da seringa foi tracionado várias vezes em sentido de vai-vem por 31/199 pacientes, $(20,3 \%)$. Um total de 77/199 (50,4\%) usou a geladeira para armazenar a seringa, sendo que os locais preferidos para guardá-las foi a porta, a prateleira superior, do meio ou inferior da geladeira. No entanto, 76/199 (49,7\%) guardaram fora da geladeira. $\mathrm{O}$ armazenamento das seringas foi feito em recipiente fechado de plástico ou isopor, 99/199 $(64,7 \%)$. Verificou-se que 31/199 (20,3\%) utilizaram outros critérios de armazenamento como guardá-las em recipiente de vidro, saco plástico ou caixa de papelão e 16/199 (10,4\%) não protegeram a seringa que é reutilizada.

A dor e agulha romba foram os principais motivos para o descarte da seringa reutilizada, apontando 83/199 (54,2\%). Entre outros motivos, 59/199 (38,6\%) destacaram-se as orientações recebidas pelos profissionais de saúde ou critério próprio do responsável do paciente, no entanto $103(67,3 \%)$ dos responsáveis receberam orientação de reaproveitamento das seringas no Hospital e Unidade Básica de Saúde. Entre outros locais de aprendizado destacaram-se as associações filantrópicas de assistência ao diabético e o próprio domicílio 50/199 (32,6\%).

Verificou-se que o enfermeiro, o médico, o auxiliar de enfermagem e o farmacêutico foram os responsáveis pela orientação da prática de reutilização de seringas 109/199 $(71,2 \%)$, sendo o enfermeiro o maior responsável pela orientação fornecida a 53/199 (34,6\%) Outras maneiras de aprendizado como conversas informais com pacientes ou vizinhos compreendeu 44/199 (28,8\%).
Em relação à descrição das alterações mais freqüentes nos locais de aplicação da insulina na população e associação dessas alterações entre os Grupos A e B, observouse que os nódulos foram encontrados com maior freqüência nos braços 19/31 (61,3\%) e com menor freqüência na região glútea $3 / 31(9,7 \%)$. As lipohipertrofias foram encontradas com maior freqüência nos braços $28 / 53(52,8 \%)$ sendo a coxa a menos afetada $3 / 31(9,7 \%)$.

Os dois grupos (A e B) apresentaram nódulos e lipohipertrofias. A comparação entre os grupos, com relação à freqüência de nódulos não evidenciou diferença estatisticamente significante $(\mathrm{p}=0,224)$. A freqüência de lipohipertrofias nos dois grupos também não se mostrou associação estatística significante $(\mathrm{p}=0,70)$.

Nenhum dos participantes teve dor, hematoma, hiperemia e lipoatrofia nos locais de aplicação de insulina. As freqüências foram tão baixas $(<3)$ em ambos os grupos que impossibilitou qualquer comparação estatística. Em relação a abscessos e prurido, não houve nenhum caso registrado.

Ao associar as alterações mais freqüentes nos locais de aplicação de insulina com o tamanho da agulha e número de aplicações de insulina fixa diária pela população e o número de reutilizações no Grupo A, não mostrou associação estatisticamente significante entre a presença de nódulos e lipohipertrofias com o tamanho da agulha. Não houve associação estatisticamente significante entre a presença de nódulo e lipohipertrofias com a freqüência de insulina fixa diária. Não houve associação estatisticamente significante entre a presença de nódulos e lipohipertrofias com o número de reaproveitamento das seringas descartáveis.

\section{DISCUSSÃO}

Os fatores econômicos ou a falta de padronização da Secretaria de Saúde na distribuição dos materiais e medicação para os pacientes, produz incremento progressivo da prática de reutilização. Isso preocupa os profissionais de saúde por não existir padronização e aprovação pelo Ministério da Saúde nem orientação dos fabricantes por afirmarem que a prática pode desencadear alterações nos locais de aplicação e danificar o material. No entanto, a clientela diabética aplica estratégias variadas, muitas vezes, com critério próprio, motivo que tem levado pesquisadores a estudar o assunto.

Em uma análise bibliográfica de pesquisas publicadas de 1978 a 2004, em diversos países, sobre reutilização de seringas descartáveis, os autores encontraram uma freqüência de reutilização de uma a trinta e nove vezes; sendo que o maior percentual apontou de 4 a 7 vezes ${ }^{(11)}$. Vale destacar que algumas pesquisas nacionais apontam médias de reutilização similares entre 2 a 4 vezes $^{(11-12)}$. Portanto a presente pesquisa corrobora com esses dados, pois a população do estudo apontou entre 1 a 4 reutilizações. No entanto, na prática de
Reutilização de seringas descartáveis no domicílio de crianças e adolescentes com diabetes mellitus Castro ARV, Grossi SAA. 
reutilização, deve-se considerar também, a deterioração do material, em relação à agulha, êmbolo e cilindro, especialmente se relacionamos com o número excessivo de reutilizações. O desgaste da agulha é comum, pois a torna rombuda diminui o lubrificante (silicone) e facilita a quebra o que compromete o conforto do paciente ${ }^{(13)}$. Os fabricantes alertam para a formação de cristais de insulina, acúmulo de resquícios de metal que obstruem a agulha e alterações microscópicas no bisel e aparecimento de microtraumas ${ }^{(8)}$.

A necessidade de atualizar as Portarias 3, 4 e 8 da Divisão de Medicamentos de 7 de fevereiro de 1986 da Agência Nacional de Vigilância Sanitária do Ministério da Saúde (ANVISA) que próibem o reprocessamento dos artigos médico-hospitalares de uso único, em todo o território nacional, levou o Ministério da Saúde a elaborar documentos para consultas públicas, considerando a possibilidade de reuso de alguns materiais em algumas situações controladas $^{(14-15)}$. As recomendações deixam claro que os produtos médico-hospitalares podem ser reprocessados segundo protocolos estabelecidos e publicados através de Resolução da Diretoria Colegiada pela ANVISA. Ainda, na reunião do Núcleo de Apoio ao Controle de Infecção Hospitalar (NACI), foi discutido o tema controverso de reprocessamento de artigos de uso único, com destaque do custo/benefício dos materiais. Deixam claro uma série de cuidados de limpeza com produtos apropriados, bem como a responsabilidade de um comitê institucional com protocolos que acompanhem os materiais reprocessados.

Um critério consistente pelos pesquisadores para recomendar a reutilização das seringas descartáveis é a falta de evidências de risco, a exclusividade no uso do material e a presença de aditivos bacteriostáticos na insulina como o metacresol, fenol e glicerol, que inibem o crescimento bacteriano $^{(16-18)}$. O fenol é considerado anti-séptico, desinfetante e fungicida de ampla ação, porém pouco efetivo contra esporos. Sua ação sobre as bactérias gram negativas vegetativas consiste em desnaturalizar as proteínas. Sua eficácia diminui em meio alcalino, baixas temperaturas e presença de material orgânico como sangue. Em concentrações de até $1 \%$, atua como bacteriostático. Como as insulinas contêm $0,0065 \%$ de fenol, atuam como bacteriostático, o metacresol, considerado desinfetante, anti-séptico tópico, antifúngico e insolúvel em glicerol e água, atuam como bacteriostático até $0,03 \%$. No caso das insulinas contêm $0,16 \%$ desse aditivo, portanto, também atua como bacteriostático $^{(19)}$. O glicerol, apesar de ser usado como emoliente e lubrificante, também possui ação antimicrobiana fraca, pois sua composição contém moléculas de álcool ${ }^{(20)}$. Pode-se ressaltar que a importância dos aditivos para controlar a proliferação de microrganismos, não leva em consideração o $\mathrm{Ph}$ da insulina de 7 , visto que pode facilitar o crescimento de algumas bactérias, como as neutrófilas, acidófilas e alcalinófilas, que se adaptam em meios orgânicos que tenham um $\mathrm{Ph}$ entre 5 e $9^{(21)}$.
Alguns estudos indicam a presença de microrganismos no instrumental decorrente das práticas de reutilização ${ }^{(22-23)}$ e o risco de produzir infecções nos locais de administração de insulina ${ }^{(24)}$. Em uma análise bibliográfica realizada os estudos apontam alterações bacteriológicas no instrumental reutilizado, destacando-se os estafilococos epidermidis $(45,45 \%)$ e bacillus sp $(18,18 \%)$ considerados parte da microbiota da pele ${ }^{(11)}$. A presença de estafilococos aureus é motivo de preocupação entre os pesquisadores, pois são considerados microrganismos patogênicos que podem causar infecções sistêmicas graves. No entanto, a proliferação dessas bactérias representa mínimo risco para produzir infecção em potência $10^{5}$, mesmo em pacientes com diabetes que são mais susceptíveis a elas ${ }^{(25)}$.

A presença de infecções em pacientes com diabetes é controvertida, alguns autores defendem que a má função intrínseca dos leucócitos polimorfonucleares tem sido considerada uma causa potencial para aumentar a infecção bacteriana, tanto em indivíduos diabéticos quanto nos pacientes não diabéticos, mesmo em caso de hiperglicemia ${ }^{(25)}$. Além disso, o acúmulo de depósitos de lipídios nos pequenos vasos pode levar a insuficiência vascular causada por fluxo sangüíneo e oxigênio baixo, mobilização de granulocitose e fatores plasmáticos, o que predispõe ao aumento de microrganismos anaeróbios e a infecções ${ }^{(26)}$. A má função metabólica nos pacientes diabéticos pode diminuir a quimiotaxia dos leucócitos e sua capacidade para atacar microrganismos nas infecções ${ }^{(27-29)}$.

Quanto ao local de guarda das seringas, estudos mostram que, quando as seringas reutilizadas são guardadas na geladeira, há proliferação de vários microrganismos como staphylococcus $s p$, staphylococcus aureus, stphylococcus epidermidis, corinebacterium $^{(22-23)}$, staphylococcus coagulase negativo, diphteroides, sptreptococcus viridians, streptococcus não hemolítico, enterobacter cloacal ${ }^{(22)}$. No congelador, pesquisas verificam também crescimento de microrganismos em seringas reutilizadas; embora, em pouca quantidade, enterobacter e bacilos gram negativos $^{(23)}$. Fora da geladeira também houve crescimento de microrganismos em seringas reutilizadas, parecidos aos que proliferam dentro da geladeira, como os staphylococcus aureus ${ }^{(30)}$. Diphteroides, staphylococcus epidermidis, alpha streptococci, e bacilos $s p^{(18)}$.

Uma pesquisa realizada com seringas esterilizadas preenchidas com insulina, mostrou que as estocadas dentro da geladeira acusaram a presença de microrganismos somente na quarta e sexta semanas ${ }^{(31)}$. Em contrapartida, as seringas preenchidas com insulina e guardadas fora da geladeira apresentaram colônias de bactérias imediatamente e na primeira, segunda, quarta, quinta e décima semanas. Contudo, as bactérias encontradas não foram biologicamente significantes nesse estudo, o que levou a sugerir estocagem fora ou dentro da geladeira, desde que o preparo e a aplicação da insulina fossem feitos com a técnica asséptica. Portanto, a conserva- 
ção do instrumental reutilizado, dentro ou fora da geladeira, é controversa, por não haver evidências convincentes de crescimento bacteriano no que se refere à eficácia de baixas temperaturas ou de temperatura ambiente ${ }^{(13)}$.

Com a falta de consenso no que diz respeito à segurança em estocar as seringas dentro ou fora da geladeira, é indispensável conhecer o comportamento dos microrganismos perante as temperaturas. Segundo a temperatura de sobrevivência, as bactérias classificam-se em mesófilas $\left(25^{\circ} \mathrm{C}\right.$ e $\left.45^{\circ} \mathrm{C}\right)$, psicrófilas $\left(20^{\circ} \mathrm{C}\right)$, psicótrofas $\left(20^{\circ} \mathrm{C}\right)$, termófilas e hipertermófilas $\left(50^{\circ} \mathrm{C} \mathrm{e} 80^{\circ} \mathrm{C}\right)^{(21)}$. Ao relacionar nossa temperatura corporal de 37 graus centígrados, pode-se pensar que possivelmente as bactérias mais encontradas nos materiais reutilizados sejam as mesófilas, psicrófilas e psicótrofas. Isso nos leva a refletir a necessidade de um conhecimento maior desses microrganismos com intuito de poder guardar a seringa reutilizada no local mais adequado e prevenir qualquer tipo de complicação nos locais de aplicação de insulina.

Em relação a dor, geralmente exacerbada pelas alterações físicas da agulha decorrentes da reutilização, também foi descrita em outros estudos como motivo de troca do material ${ }^{(17)}$. Como outros autores, acredita-se que o conhecimento adquirido pelos pacientes e responsáveis, por meio da orientação dos profissionais e busca pessoal de informações tenha influenciado na decisão sobre a melhor maneira de reaproveitamento ${ }^{(17-18,23)}$, o que reforça a necessidade de que os serviços continuem a se empenhar nas orientações específicas e padronizadas sobre os riscos e benefícios dessa prática. As agulhas rombudas, decorrentes do reuso, têm sido apontadas como motivo para a troca de seringa nesse e em outros estudos ${ }^{(30,32)}$. Para elucidar essa questão, um estudo interessante foi desenvolvido sobre o dano ocasionado em agulha nova, pela passagem da mesma através da tampa de borracha do frasco de insulina $^{(33)}$. A força necessária para transpor a borracha do frasco foi medida por um transdutor, durante 17 inserções iniciais e 17 subseqüentes. Não houve diferença estatisticamente significante entre as pressões das inserções iniciais e subseqüentes das agulhas, já que não houve deformação mesmo com múltiplas inserções. Para acontecer essa deformação seria necessária maior força para penetrar a borracha. Além disso, as fotografias microscópicas das pontas das agulhas, não evidenciaram tortuosidade ou qualquer tipo de dano, mas apenas alguma evidência de deterioração do silicone como resultado das múltiplas inserções.

O fato do hospital ser o maior responsável pelo ensino da prática de reutilização, leva-nos a refletir sobre a importância da criação de protocolos institucionais que considerem a realidade da clientela e direcionem as orientações para pacientes e familiares. Considerando que as associações de diabéticos e as Unidades Básicas de Saúde (UBS) também contribuem de forma importante no ensino do reaproveitamento de seringas, há necessidade desses serviços reverem suas práticas, no sentido de capacitar melhor os profissionais de saúde. É motivo de preocupação o fato do aprendizado sobre a reutilização estar acontecendo por meio de troca de experiências informais; dessa forma, é de fundamental importância que o enfermeiro realize uma avaliação periódica dessa prática.

Em relação às alterações mais freqüentes nos locais de aplicação de insulina, tanto os nódulos quanto as lipohiperdistrofias foram apontadas nos locais de aplicação de insulina em ambos os Grupos. As lipohipertrofias, massas cutâneas de gordura e tecido fibroso, podem ser causadas por repetidas injeções de insulina no mesmo local, onde a absorção de insulina torna-se reduzida e a sensibilidade diminuída ${ }^{(28)}$. Essas complicações podem estar associadas a uma série de fatores e não somente a microtraumas causados pelas agulhas reutilizadas ${ }^{(33)}$. Parece que o componente lipogênico de algumas insulinas (grau de pureza) mediando por processos imunes do indivíduo pode desencadear lipodistrofias e fibrose nos locais de aplicação. Em casos avançados, torna-se menos vascularizado com perda da sensibilida$\mathrm{de}^{(34)}$. As lipohiperdistrofias poderiam estar relacionadas também, com alterações do metabolismo dos lipídeos e carboidratos associados à resistência insulínica ${ }^{(35)}$.Alguns autores ${ }^{(36)}$ explicam que a pele do paciente diabético sofre uma série de alterações na epiderme, derme superior, fibras elásticas e colágenas e alterações vasculares, que associadas a uma hiperglicemia mantida por algum tempo, provoca hiperglicosilação não enzimática no colágeno e em todas as proteínas do organismo.

Estudos sugerem a relação entre as lipohiperdistrofias com o aumento significativo dos níveis de imunoglobulinas A (anticorpos IA) após iniciar o tratamento com insulina ${ }^{(37)}$.

Quanto a presença de nódulos e lipodistrofias pode haver relação com a deformidade das agulhas reutilizadas, as quais podem causar microtraumas ${ }^{(8)}$. A presença de nódulos e lipohipertrofias ocorreram com maior freqüência nos braços, região essa utilizada, preferencialmente, pela totalidade dos pacientes. Aregião glútea foi a menos afetada com relação a presença de nódulos, embora bastante utilizada também pelos crianças e adolescentes. Isso se explica pelo fato da região glútea, em crianças e adolescentes, apresentar maior quantidade de tecido subcutâneo que a dos braços ${ }^{(37)}$. A região da coxa foi a menos afetada com relação à presença de lipohipertrofias, embora bastante utilizada também. Contudo pode ser provável que isso decorra do fato das crianças e adolescentes serem extremamente ativos o que facilita a absorção da insulina nessa região.
Reutilização de seringas descartáveis no domicílio de crianças e adolescentes com diabetes mellitus Castro ARV, Grossi SAA. 
A comparação entre os grupos A e B com relação a presença de nódulos e lipohipertrofias não evidenciou diferença estatisticamente significante $(\mathrm{p}=0,05)$, ou seja, o grupo que reutiliza seringas descartáveis não apresentou mais nódulos e lipohipertrofias do que o grupo que não reutiliza. Não foram encontrados na literatura estudos que associaram a presença de nódulos e hipertrofia com a prática de reutilização.

Outras alterações encontradas nos locais de aplicação de insulina foram dor, hematoma, hiperemia e lipoatrofia que se apresentam com freqüências baixas e, por este motivo, não foi possível qualquer comparação estatística. Entretanto, a literatura descreve a possibilidade da ocorrência dessas alterações em pacientes em uso de insulina ${ }^{(38)}$.

Em relação ao tamanho da agulha e número de injeções de insulinas fixas diárias, não foram encontradas associações estatisticamente significantes entre a presença de nódulos e lipohipertrofias na população. Sabe-se que no esforço de encorajar os pacientes a adotarem esquemas de múltiplas injeções diárias de insulina para melhorar o controle glicêmico, com mais conforto na aplicação de insulina, os fabricantes produziram agulhas mais finas e mais curtas entre $5 \mathrm{~mm}$ e $15 \mathrm{~mm}$ das observadas no mercado. A preocupação com o tamanho e material da agulha surge pelas injúrias e principalmente, pelas injeções intramusculares com agulhas maiores, levando à absorção mais rápida e a hipoglicemia ${ }^{(39)}$.

O conhecimento de alguns aspectos como tamanho de agulha, espessura da pele e tecido subcutâneo em algumas áreas do corpo é importante por minimizar as possíveis complicações locais e flutuações glicêmicas indesejadas no controle metabólico, associadas com a variabilidade dos tamanhos de agulhas dos sistemas de injeção.

Não foi encontrada associação estatisticamente significante entre o número de reutilizações de seringas descartáveis e a presença de nódulos e lipohiperdistrofias no Grupo A, ou seja, que o número de reutilizações não estaria associado diretamente à presença dessas complicações locais. Pode-se pensar que essas complicações podem estar associadas a fatores intrínsecos individuais, como a técnica incorreta de aplicação de insulina, abuso de reutilizações de seringas, falta de rodízio dos sítios de aplicação, bem como características químicas das insulinas e fatores imunológicos dos pacientes, facilitando a presença de lipohipertrofias e de nódulos.

\section{CONCLUSÕES}

Na população estudada, identificou-se a prevalência do sexo feminino em $65,3 \%$ com $53,8 \%$, dos pacientes provenientes da cidade de São Paulo. O Ensino Fundamental e médio dos pacientes apontou $78,5 \%$. A renda familiar predominante foi de 1 a 2 salários mínimos $(48,8 \%)$, sendo que a as rendas familiares dos Grupos A e B teve uma mediana de 3 salários mínimos.
Em relação ao local de aquisição das seringas, $65,3 \%$ dos pacientes compram na farmácia e $25,1 \%$ adquiriram na Unidade Básica de Saúde. A maioria dos pacientes $(82,4 \%)$ gasta de 20 a 79 reais por mês, ou seja, de 8 a 27 dólares pela compra de seringas.

Tanto o paciente $(55,8 \%$ ) quanto a mãe $(38,7 \%)$ são responsáveis pelo preparo e aplicação da insulina. O produto usado para o preparo $(58,3 \%)$ e aplicação de insulina $(57,3 \%)$ foi o álcool de supermercado. A maioria da população $(97,5 \%)$ tem o hábito de lavar as mãos antes do preparo e na aplicação de insulina. Apenas 2,5\% não realizam essa prática.

Os locais preferidos para aplicação da insulina foram os braços $(92 \%)$ e as coxas $(82 \%)$ com menor preferência pelo glúteo $(79 \%)$ e o abdômen $(75 \%)$. Houve uma média de três aplicações de insulina no mesmo local em uma semana.

A comparação da idade entre os Grupos A e B evidenciou que a idade média do Grupo A, que reutiliza, é de 11 anos e do Grupo B, que não reutiliza, foi de 9 anos. A freqüência maior de reaproveitamento de seringas foi de 1 a 4 vezes, $(77,8 \%)$.

As estratégias de reutilização das seringas foram variadas, predominando o reencape da agulha com o próprio protetor sem limpeza previa $(60,1 \%)$, sendo que os locais preferidos para armazenar as seringas foram dentro $(50,4 \%)$ e fora da geladeira $(49,6 \%)$ acondicionadas em recipientes fechados $(64,7 \%)$ de plástico ou isopor.

O motivo mais apontado para a troca da seringa foi a dor $(39,2 \%)$ e outros $(31,6 \%)$, como orientações pelos profissionais de saúde ou critério próprio dos pacientes e responsáveis.

O local de aprendizado da prática de reutilização foi o hospital $(52,3 \%)$ seguido por outros locais $(32,6 \%)$ como associações filantrópicas de assistência ao diabético e o próprio domicílio. O maior responsável pela orientação de reutilização foi o enfermeiro, apontando 34,6\%. Outras maneiras de aprendizado foram as conversas informais com pacientes ou vizinhos $(28,8 \%)$.

As complicações mais freqüentes nos locais de aplicação da população foram os nódulos e as lipohipertrofias. O braço teve o maior número de lipohipertrofias $(52,8 \%)$ e de nódulos $(61,3 \%)$.

A associação entre as complicações mais freqüentes (nódulos e lipohipertrofias) entre os Grupos A e B não evidenciou diferença estatisticamente significante, o que quer dizer que ambos os grupos apresentam complicações independente de reutilizar ou não as seringas.

A relação entre a presença de nódulos e lipohipertrofias com o tamanho da agulha verificou-se que não houve diferença estatisticamente significante, o que evidencia a falta de relação direta entre as complicações com o tamanho de agulha. Quanto à presença de nódulos e lipohipertrofias, da população, e sua relação com a insulina fixa diária também não 
houve associação estatisticamente significante, o que nos leva a pensar que a presença dessas complicações não estaria relacionada diretamente com o número de insulinas que $o$ paciente administra diariamente.

Em relação ao número de reutilizações com a presença de nódulos e de lipohipertrofias também não houve diferença estatisticamente significante, quer dizer que a prática de reutilização não está relacionada diretamente com esse tipo de complicações.

\section{CONSIDERAÇÕES}

Com o presente estudo pode-se analisar que a prática de reutilização não está diretamente relacionada com a presença de complicações nos locais de aplicação de insulina, pois existem outras variáveis que possam influenciar como apreciamos no desenvolvimento desta pesquisa. No entanto não se observou nenhum tipo de complicação que se possa atribuir à reutilização de seringas, tanto nesta investigação quanto em outras já realizadas desde a década de 70 .

Embora a população deste estudo, tenha contemplado a totalidade dos pacientes atendidos no Instituto da Criança, não é possível generalizar os resultados por abranger um número limitado de pacientes. Para isso, torna-se fundamental o desenvolvimento e aprofundamento de pesquisas que esclareçam essas questões para oferecer segurança ao profissional que lida com pacientes diabéticos e possibilite melhor direcionamento das ações educativas referentes à prática de reutilização das seringas descartáveis. Sendo assim, haverá subsídios que permitam corroborar resultados desta pesquisa relativos à prática em questão.

Apesar de que a prática de reutilização de seringas descartáveis para aplicação da insulina não deva ser amplamente estimulada pelo enfermeiro, cabe a esse profissional discutir com os responsáveis das crianças e adolescentes sobre a problemática em questão, sendo imprescindível dar liberdade ao paciente e ao familiar de fazer suas escolhas tendo em vista a disponibilidade de seus recursos. Se a opção for pelo reaproveitamento do material, é fundamental que eles se sintam acolhidos durante o processo de decisão e encorajados a assumirem responsabilidade decorrente dessa decisão. Contudo é necessário levar em consideração alguns aspectos importantes, a saber, a avaliação inicial e periódica do paciente e responsável, pela equipe que o assiste, as orientações relacionadas aos cuidados antes, durante e após a reutilização das seringas, bem como o conhecimento, dessa prática, da instituição que dá assistência a esses pacientes.

\section{REFERÊNCIAS}

1. White F, Nanan D. Status of national diabetes programmes in the Américas. Bol World Health Organ. 1999;77(12):981-7.

2. Implementation of treatment protocols in the Diabetes Control and Complications Trial. Diabetes Care. 1995;18(3):361-76.

3. Pozzan R,Cunha E, Portela E, BarabosaK, Magalhães A, Cunha $\mathrm{M}$, et al. Experiência com programa de educação para pacientes diabéticos com baixo nível socio-econômico. Rev Bras Enferm. 1994;7(3):241-9.

4. Souza CR. A prática da reutilização de seringas descartáveis na administração de insulina no domicílio [dissertação]. Ribeirão Preto: Escola de Enfermagem de Ribeirão Preto, Universidade de São Paulo; 1999.

5. Brasil. Lei n. 10782, de 9 de março de 2001. Define diretrizes de política de prevenção e atenção integral à saúde da pessoa portadora de diabetes [legislação na Internet]. Brasília; 2001. [citado 2003 maio 3]. Disponível em: www.diabetes.org.br/diabetes/ legislaçao/le10782.php

6. Ciechanowski P, Katon W, Russo J. Depression and diabetes impact of depressive symptoms on adherence, function, and costs. Arch Intern Med. 2000;160(21):3278-85

7. Agência Nacional de Vigilância Sanitária (ANVISA). Consulta Pública n. 98, de 6 de dezembro de 2001. Dispõe sobre produtos médicos de uso único e o reprocessamento do grupo de produtos médico-hospitalares que especifica e dá outras providência [legislação na Internet]. Brasilia; 2001. [citado 2003 mar. 4]. Disponível em: www.anvisa.gov.br
8. Caffrey RM. Are all syringes created equal? Am J Nurs. 2003;103(6):46-9,55.

9. Damasceno M, Rocha T, Lino R, Carvalho Z. Problemas identificados na clientela diabética: análise quantiqualitativa. Rev Enferm UERJ. 1995;3(1):19-28.

10. Grossi SA. Avaliação de dois esquemas de monitorização domiciliar em pacientes com diabetes mellitus do tipo 1 [tese]. São Paulo: Escola de Enfermagem, Universidade de São Paulo; 1999.

11. Castro A, Grossi SA. Reutilização de seringas e agulhas descartáveis na aplicação de insulina pela clientela diabética: uma análise da literatura. Nursing (São Paulo). 2004;7(77):22-8.

12. Scain S. Reutilização de seringa descartável para aplicação de insulina. Rev Hosp Clin Porto Alegre. 1985;5(2):181-5.

13. American Diabetes Association. Insulin administration. Diabetes Care. 2004;27 Suppl 1:S106-9.

14. Brasil. Ministério da Saúde. Divisão Nacional de Vigilância Sanitária de Medicamentos. Portaria n. 4, de 7 de fevereiro de 1986. Dispõe sobre a inclusão de artigos correlatos na definição de artigo médico-hospitalar. Diário Oficial da União, Brasília, 12 fev. 1986. Seção 1, p. 23-7.

15. Agência Nacional de Vigilância Sanitária (ANVISA). Consulta Pública n. 17, de 19 de março de 2004. Proposta de reesterilização, reprocessamento, protocolo e diretrizes [legislação na Internet]. Brasília; 2004. [citado 2004 jun. 20]. Disponível em: www. anvisa.gov.br 
16. Grossi S. Aspectos práticas da administração de insulina com seringas. BD Terapêutica Diabetes. 2004;31(1):1-3.

17. Aziz SH. Recurrent use of disposable syringe-needle units in diabetic children. Diabetes Care. 1984;7(2):118-20.

18. Panamonta $\mathrm{O}$, Angsusingha $\mathrm{K}$, Tuchinda $\mathrm{CH}$, Punnadanta L, Hongsiriwan S. Reuse of disposable insulina syringes and needles in diabetic children. J Med Assoc Thai. 1989;72(6):314-6.

19. Goodman L, Gilman AG. As bases farmacológicas da terapêutica. 10 a ed. Rio de Janeiro: McGraw Hill; 2003.

20. Martindale. The extra pharmacopeia. $29^{\text {th }}$ ed. London: London the Pharmaceutical Press; 1989.

21. Trabulsi LR. Microbiologia. São Paulo: Atheneu; 1996.

22. Hissa M, Montenegro R, Colares F. Reutilização de seringas descartáveis de insulina: diminuição de custos no tratamento do diabetes insulino-dependente. Arq Bras Endocrinol Metabol. 1987;31(4):78-80.

23. Stepanas TV, Turley H, Tuohy EA. Reuse of disposable insulin syringes. Med J Aust. 1982; 1(7):311-3.

24. Jackson PG, Keen H, Noble CJ, Simmons NA. Infection abscesses in diabetic due to mycobacterium chelonei var abscessus. Br Med J. 1980;281(6248):1105-6.

25. Elek SD. Experimental staphylococcal infection in the skin of man. Ann N Y Acad Sci. 1956;65(3): 85-90.

26. Muniz EC, Rocha RM, Reis ML, Santos VL, Grossi SA. Neuropathic and ischemic changes of the foot in Brazilian patients with diabetes. Ostomy Wound Manage. 2003;49(8):60-70.

27. Grossi SA. Prevenção de úlceras nos membros inferiores em pacientes com diabetes mellitus. Rev Esc Enferm USP. 1998;32(4):377-85.

28. Fuenzalida H, López P, Echart C. Manifestaciones cutáneas em pacientes com diabetes mellitus. Rev Hosp Clin Univ Chile. 1999;10(2):130-7.
29. Robertson H, Polk H. The mechanism of infection in patients with diabetes mellitus: a review of leukocyte malfunction. Surgery. 1974;75(1):123-8.

30. Collins BJ, Richardson SG, Spence B, Hunter J, Nelson JK. Safety of reusing disposable plastic insulin syringes. Lancet. 1983;1(8324):559-61.

31. Oberly K, Clark J, Paulshock B, Delaware W. Sterility of insulin stores in syringes [letters]. Diabetes Care. 1979;2(6):531.

32. Oli JM,Gugnani H, Ojieabre G. Multiple use of ordinary disposable syringes for insulin injections. Br Med J. 1982;284:236.

33. Kline D, Kuhn T. Needle reuse and tip damage. Diabetes Care. 2004;27(2):617.

34. Paglione A, Ferrari G, Berg G, Frechtel G, Taverna M. Lipodistrofia parcial adquirida resistencia insulínica, actividad lipasa hepática y partículas LDL pequenas y densas. Medicina 2001;61(1):81-4.

35. Palitot EB, Anjos GA, Lima FHSD, Azzouz M. Manifestações cutâneas no diabetes "mellitus": atualização bibliográfica. J Bras Med. 2000;78(6):136,138,141-2.

36. Vera M, Shumkou G, Guell R. Cambio histológico e histoquímico em la piel de pacientes diabéticos insulinodependientes. Rev Cub Med. 1987;26(2):125-33.

37. Huemer C, Kitson H, Malleson P. Lipodistrophy in patients with juvenile dermatomyosite-evaluation of clinical and metabolic abnormalities. J Rheumatol. 2001;28(3):610-5.

38. Camata D. Complicações locais na pele, relacionadas a aplicação de insulina. Rev Lat Am Enferm. 2003;11(1):119-22.

39. Tubiana N, Belarbi N, Fediaevsky L, Polak M, Kakou B. Short needles $(8 \mathrm{~mm})$ reduce the risk of intramuscular injections in children with type 1 diabetes. Diabetes Care. 1999;22(10):1621-5. 